\title{
ESTUDO COMPARATIVO ENTRE REVESTIMENTOS DE GESSO E ARGAMASSA MISTA MANUAL E PROJETADA
}

\author{
COMPARATIVE STUDY BETWEEN PLASTER COATINGS AND MIXED MORTAR \\ MANUAL AND PROJECT
}

\section{RESUMO}

A necessidade de acelerar e aperfeiçoar os processos construtivos da construção civil, induz os agentes envolvidos buscar novos métodos que auxiliem no maior desempenho dos materiais utilizados. Este artigo objetiva analisar a viabilidade da implantação do método de projeção de argamassas e gesso para revestimento interno, comparada com o revestimento aplicado manualmente, considerando produtividade e custo, bem como a qualidade construtiva de cada método. $O$ comparativo foi realizado numa edificação vertical na cidade de João Pessoa PB. O processo de projeção da argamassa mista trouxe significativos ganhos de eficiência, se comparado aos demais processos estudados, uma vez que mesmo associado a um custo final maior, destacou-se por apresentar um bom acabamento final e maior área revestida no mesmo tempo. Verificou-se também os procedimentos necessários para emprego dos equipamentos utilizados no revestimento projetado e manual. A partir dos resultados obtidos, foi possível a escolha do revestimento interno a ser utilizado na edificação vertical.

Palavras-chave: Edificações. Revestimento. Argamassa.

\section{ABSTRACT}

The necessity of acceleration and improvement on constructive processes of civil construction induces the agents involved to seek new methods that advances the materials performance. The objective of this research is to analyze the feasibility of the implantation of mortar projection for internal lining, compared to the coating

1 Graduada em Engenharia Civil pelo Centro Universitário de João Pessoa (UNIPÊ). E-mail: girlandiasampaio@yahoo.com 2 Especialista em Instalações Prediais pela Universidade Potiguar (UNP), com MBA em Gestão Empresarial pela Fundação Getúlio Vargas (FGV). Docente do Centro Universitário de João Pessoa (UNIPÊ). E-mail: clovis.santos@unipe.br

3 Especialista em Engenharia de Instalações Prediais pelas Faculdades de Ensino Superior da Paraíba (FESP). E-mail: kenyrodrigues. prof@gmail.com

4 Graduanda em Engenharia Civil pelo Centro Universitário de João Pessoa (UNIPÊ). E-mail: rbizerris@yahoo.com.br 
applied manually, considering productivity, cost, adhesion and quality of each constructive method. The comparison was made in a vertical building in the city of João Pessoa - PB. When compared to the other process studied, the projection of mixed mortar brought significant efficiency gains even associated with a higher final cost, outstanding by having a good visual aspect and covering a larger area at the same amount of time. Also, this research checked the necessary procedures for projected and manual mortar equipment. Also, this research checked the necessary procedures for projected and manual mortar equipment. As a result it was possible to choose the internal lining to be used in the vertical building.

Keywords: Mortar. Coating. Edification.

\section{INTRODUÇÃO}

A busca por maior produtividade e uma boa logística no canteiro da obra induz as construtoras a adotarem tecnologias ou sistemas que tragam avanços significativos quanto à diminuição de desperdícios, agilidade nas tarefas diárias e agregam economia.

Os processos adotados para execução de determinados serviços, devem ser estudados antes de serem utilizados nas obras, devido às variáveis existentes como preço, prazo de obra, qualidade de acabamento e disponibilidade de material na região.

Responsáveis pelo bom desempenho de outros componentes, as argamassas utilizadas no revestimento devem ser escolhidas baseadas em estudos das características de desempenho, produtividade, custos e perdas. Cada serviço possui sua particularidade, apresentando diferenças também no processo de produção, armazenamento e de industrialização, ficando a critério do empreiteiro, com aporte de sua equipe técnica, a escolha do sistema a ser adotado analisado suas particularidades (ABCP, 2002).

Sendo usada para revestimento interno, a argamassa deve apresentar um conjunto de propriedades que possibilitem o cumprimento de suas funções, destacando-se a regularização dos elementos de vedação para o recebimento do acabamento final, auxílio no isolamento térmico e acústico e na absorção de tensões.

Assim, cabe referir que o objetivo geral desse artigo é analisar a viabilidade de implantação do método de projeção da argamassas e gesso para revestimento interno, comparada com revestimentos aplicados manualmente, considerandose produtividade e custo, bem como a qualidade construtiva de cada método. Para cumprir o objetivo acima referido, foram traçados como objetivos específicos: estudar as propriedades das argamassas e gesso para revestimentos; apresentar as resultados do desempenho mecânico dos sistemas de revestimento; apropriar 
produtividade e custos de execução do revestimentos em argamassa nos processos manual e projetado; e promover uma revisão com base nos marcos teóricos; e em caráter metodológico, referir aspectos da experiência confirmada por um estudo de caso em uma construtora de João Pessoa, capital litorânea da Paraíba.

A presente pesquisa é de grande relevância, pois traz dados que possibilitam não só a escolha do revestimento interno da edificação estudada, mas de qualquer edificação vertical cujos substratos das paredes recebam revestimentos em gesso e argamassa. Traz também, informações não somente ligada a custos, mas a produtividade e qualidade em acabamentos, que são também parâmetros para escolhas de revestimentos.

\section{ARGAMASSAS E GESSO PARA REVESTIMENTOS INTERNOS E SUAS APLICAÇÕES NA CONSTRUÇÃO CIVIL}

\section{ARGAMASSAS}

A NBR 13281 (ABNT, 2005) define argamassa como uma mistura homogênea de agregado(s) miúdo(s), aglomerante(s) inorgânico(s) e água, contendo ou não aditivos ou adições, com propriedades de aderência e endurecimento, podendo ser dosada em obra ou em instalação própria (argamassa industrializada).

Tanto como responsáveis pelo assentamento entre os blocos de alvenaria como no revestimento, a constituição da argamassa é significativa para obtenção de propriedades como resistência, resiliência e impermeabilidade.

A NBR 13529 (ABNT, 2013) define o revestimento de argamassa como cobrimento de uma superfície com uma ou mais camadas superpostas, apta a receber acabamento decorativo ou constituir-se em acabamento final. Os substratos existentes numa edificação, ou seja, as bases sobre a qual serão aplicados os revestimentos brutos são os elementos estruturais da edificação (pilares e vigas) e os elementos de vedação (tijolos cerâmicos ou blocos de concreto).

As argamassas usadas no emboço de alvenarias têm como principal função criar uma camada de proteção com espessura e acabamento uniforme, contribuindo para higiene, estética e proteção do ambiente. Em emboços externos a principal função é proteger a estrutura contra agentes atmosféricos, além da função decorativa. Em geral, para execução do emboço, utilizam-se argamassas feitas no canteiro da obra e também argamassas pré-misturadas (BERTOLINI, 2006).

Os revestimentos de argamassas devem apresentar um conjunto de propriedades, tanto no estado fresco (relacionado à sua aplicação) como no estado endurecido (relacionado ao seu comportamento), que influenciam no cumprimento das suas funções de acordo com diferentes usos e aplicações. A figura 1 representa um breve resumo dessas propriedades. 
Figura 1: Propriedades das argamassas nos estados: fresco e endurecido

\begin{tabular}{|c|c|c|}
\hline $\begin{array}{l}\quad \text { ESTADO FRESCO } \\
* \text { massa específica e teor de ar } \\
* \text { trabalhabilidade } \\
* \text { retenção de água } \\
* \text { aderência inicial } \\
* \text { retração na secagem }\end{array}$ & $>$ & $\begin{array}{ll} & \text { ESTADO ENDURECIDO } \\
* & \text { aderência } \\
* & \text { capacidade de absorver } \\
\text { deformações } \\
* \text { resistência mecânica } \\
* \text { resistência ao desgaste } \\
* \text { durabilidade }\end{array}$ \\
\hline
\end{tabular}

Fonte: BAÍA; SABBATINI, 2000, p. 15.

Quanto aos tipos de argamassa, destacam-se a argamassa mista produzida no próprio canteiro e a industrializada, fornecida já ensacada.

A argamassa mista é composta por mais de um aglomerante, o cimento Portland e a cal hidratada, podendo ser incorporados aditivos. É uma argamassa tradicional, produzida na obra, onde os materiais constituintes são medidos em volume.

Segundo Guimarães (1998) nas argamassas de revestimento a presença da cal hidratada atribui maior facilidade de aplicação, plasticidade durante o endurecimento e, sobretudo, a aderência ao substrato que evita o descolamento e a fissuração.

A dosagem das argamassas mistas é normalmente feita utilizando traços tradicionais baseados em proporções volumétricas entre areia e aglomerantes, fazendo alguns ajustes na proporção de areia e água em função de sua plasticidade.

A argamassa industrializada é usada pelas construtoras para substituir a argamassa feita na obra, à base de cal hidratada e areia, a qual é fornecida de modo a necessitar apenas da adição de água no seu preparo. Uma das principais recomendações na escolha da argamassa industrializada são a composição e a especificação para o uso, respeitando as resistências do local em que a argamassa será aplicada.

A NBR 13529 (ABNT, 2013) define argamassa industrializada como produto proveniente da dosagem controlada, em instalação própria, de aglomerante(s) de origem mineral, agregado(s) miúdo(s) e, eventualmente, aditivo(s) e adição(ões) em estado seco e homogêneo, a qual necessita de adicionar a quantidade de água requerida.

Nas argamassas industrializadas propriedades como resistência à compressão e superficial, capacidade de retenção de água, teor de ar incorporado e durabilidade, devem ser verificadas ao longo do processo de seleção do fornecedor e também através de testes (YAZIGI, 2014). 
Quando se fala em execução, seja qual tipo de argamassa utilizado, o processo de aplicação do revestimento divide-se em várias etapas, com procedimentos específicos que dependem do tipo de argamassa utilizada e devem obedecer a sequência das atividades definidas por norma. No geral as etapas de execução do revestimento de argamassa resumem-se em: preparo da base, definição do plano do revestimento, aplicação da argamassa, acabamento das camadas e detalhes construtivos.

Independente da forma de aplicação, manual ou projetada, deve-se proceder a preparação da base, a qual consiste em adequar a alvenaria para o recebimento da argamassa. Essa adequação está relacionada com a limpeza da estrutura e da alvenaria, eliminação das irregularidades superiores, remoção das incrustações, pontas metálicas e preenchimento de furos bem como aumentar a rugosidade para garantir boa aderência.

De acordo com a NBR 7200 (ABNT, 1998) quando se fizer uso de argamassas as bases de revestimento devem ter as seguintes idades mínimas: 14 dias de idade para alvenarias não armadas estruturais e alvenarias sem função estrutural de tijolos, blocos cerâmicos, blocos de concreto e concreto celular, admitindo-se que os blocos de concreto tenham sido curados durante pelo menos 28 dias antes da sua utilização; três dias de idade do chapisco para aplicação do emboço ou camada única; para climas quentes e secos, com temperatura acima de $30^{\circ} \mathrm{C}$, este prazo pode ser reduzido para dois dias.

Para iniciar a aplicação da argamassa procede-se a execução do taliscamento (mestras) utilizando-se esquadro, régua de alumínio, nível de bolha e prumo As taliscas devem ser espaçadas de $1,5 \mathrm{~m}$ a 1,8 $\mathrm{m}$, considerando o comprimento da régua de alumínio. As mestras são executadas unindo as taliscas na direção vertical com aproximadamente $5 \mathrm{~cm}$ de largura.

Após o preenchimento dos vazios entre as mestras deve ser feita a compressão da argamassa com objetivo de uniformizar a superfície. O acabamento da superfície, no geral, pode ser feito desempenado, que consiste no alisamento da superfície através da passagem da desempenadeira, ou sarrafeado que deve ser feito com régua de alumínio com movimentos na vertical de baixo para cima até que a superfície esteja plana.

\section{GESSO PARA REVESTIMENTOS}

Aglomerantes simples formados por sulfatos e anidros de cálcio são chamados genericamente de gesso. A desidratação por calcinação da gipsita natural, moagem e seleção por granulometria constitui o processo industrial do gesso, que quando misturado com água entra no processo de endurecimento, dando início a pega do material aglomerante, com isso ganhando resistência. Esse 
processo depende de fatores como: temperatura e tempo de calcinação; finura; quantidade de água; impurezas ou aditivos usados (YAZIGI, 2014)

A NBR 13207 (ABNT, 1994) apresenta a definição do gesso para construção como um material moído em forma de pó, obtido da calcinação da gipsita, constituído predominantemente de sulfato de cálcio, podendo conter aditivos controladores do tempo de pega.

O gesso é utilizado como revestimento em alvenarias internas com pasta com espessura mínima de até $5 \mathrm{~mm}$. O material não é indicado para aplicações exteriores podendo decompor-se na presença de água (YAZIGI, 2014).

\section{METODOLOGIA}

A pesquisa caracteriza-se pela revisão bibliográfica de especialistas sobre o tema selecionado, pelas vertentes exploratória e descritiva, visto que inclui a parte mais exata da investigação direcionada para a explicação do fato estudado.

Esta pesquisa é dada por um estudo de caso, no qual foram analisados a produtividade, o custo, o desempenho referente à resistência ao arrancamento e o acabamento final de 4 (quatro) formas de execução do revestimento bruto interno de paredes: revestimento em gesso com aplicação manual; revestimento em gesso com aplicação projetada mecanicamente; emboço com argamassa mista de cimento, cal e areia com produção e aplicação manual; emboço com argamassa mista industrializada e com aplicação mecanizada (projetada). As análises serviram para a escolha do método construtivo do revestimento a ser utilizado em uma edificação vertical de 23 pavimentos.

A coleta de dados foi realizada em uma obra na cidade de João Pessoa-PB, composta por 39 apartamentos com área construída total de $7.929 \mathrm{~m}^{2}$ distribuída em 23 pavimentos.

Para o estudo da produtividade e do custo dos sistemas foi utilizado o método de apropriação manual dos consumos e insumos de cada serviço, com medições de áreas executadas, contagem de tempo para execução da área e verificação dos materiais utilizados para o cumprimento da tarefa. Os respectivos coeficientes dos insumos calculados em relação a $1 \mathrm{~m}^{2}$ de cada sistema foram condensados em modelos padrão de composições de custo unitário. Para que a pesquisa pudesse ter aplicação prática eficaz, os valores monetários foram fornecidos pelo departamento da empresa construtora, os quais foram os realmente cotados, após a pesquisa no mercado local.

Para avaliação do desempenho dos sistemas foram contratados os serviços de uma empresa especializada em controle de qualidade de materiais atuante na região e já consolidada na atividade para realizar o ensaio da resistência de aderência à tração, verificando-se a conformidade com a NBR 13749 (ABNT, 2013). 
O item acabamento refere-se à condição da superfície para aplicação futura de massa PVA para pinturas, considerando-se a aplicação do número de demãos de massa necessárias para o acabamento desejado para a parede. Para os padrões da empresa, considerando-se que quanto pior o acabamento do substrato, mais demãos de massa seriam necessárias, consequentemente mais custos e prazos para a realização da pintura seriam exigidos, adotou-se como parâmetro a referência: Ruim - 3 demãos; Bom - 2 demãos; Ótimo - 1 demão.

\section{ESTUDO DE CASO}

A Figura 2 apresenta a planta baixa dos apartamentos cujas paredes foram revestidas, para a realização da pesquisa. Os apartamentos possuem área total de 125,55 m², compostos por quatro quartos sendo dois suítes, sala, cozinha, área de serviço, quarto de serviço com banheiro, despensa, um banheiro social, varanda gourmet.

Figura 2: Planta do apartamento tipo

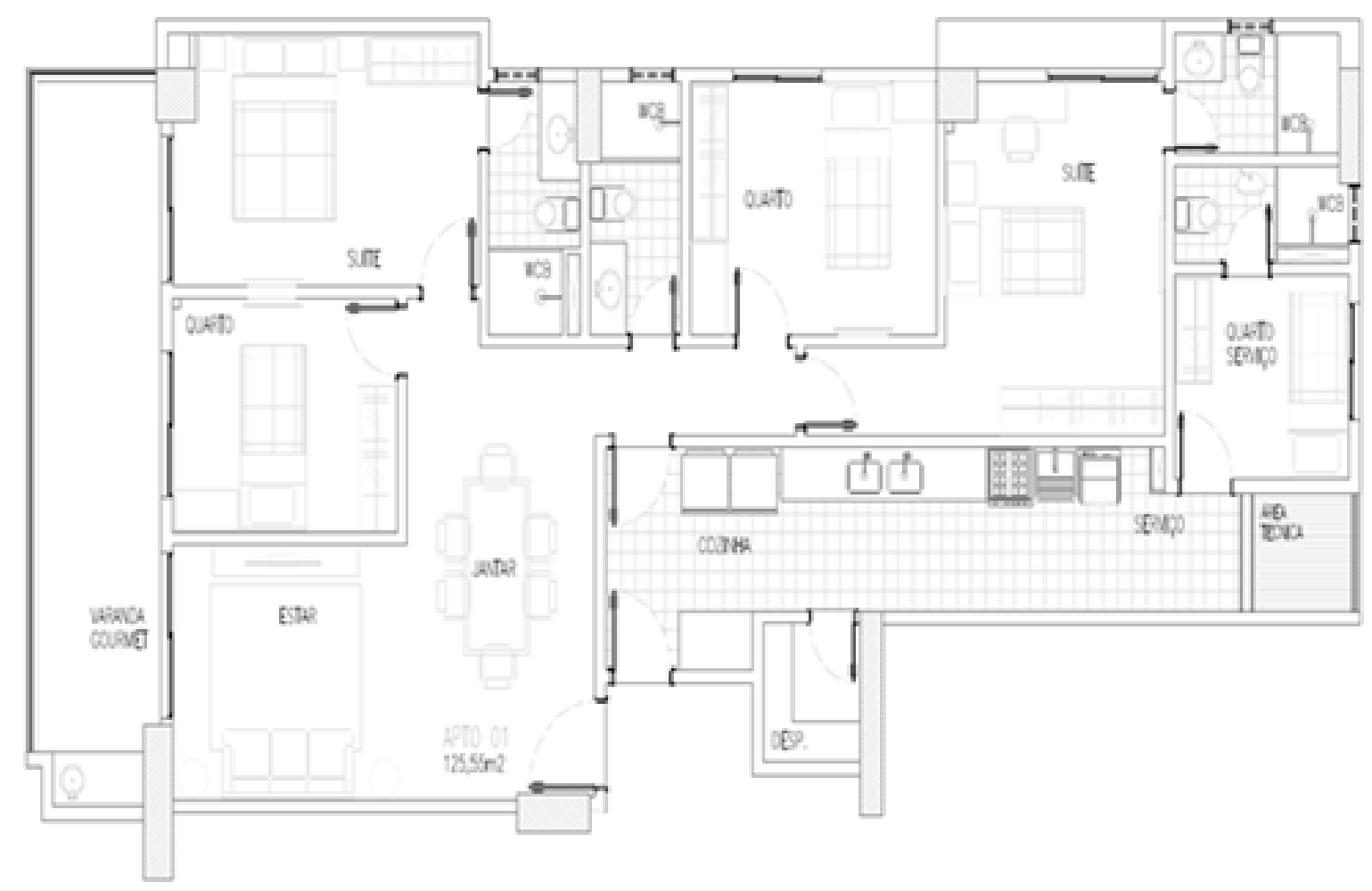

Fonte: FCK Engenharia. 


\section{REVESTIMENTO EM ARGAMASSA DE GESSO COM APLICAÇÃO MANUAL}

A área total revestida no apartamento modelo, com esse primeiro sistema, foi de $52,43 \mathrm{~m}^{2}$, por uma equipe formada por dois gesseiros.

O preparo do gesso para revestimento foi realizado em um recipiente plástico (Figura 2), dentro do próprio apartamento, misturando-se a argamassa com um misturador acoplado a uma furadeira.

O transporte do material e a sua aplicação na parede foi realizada com desempenadeira plástica apropriada. Depois de aplicadas as camadas de argamassa na parede, procedeu-se o sarrafeamento com réguas plásticas ou de alumínio (Figura 3).

Figura 3: Preparo do gesso e aplicação manual nas paredes

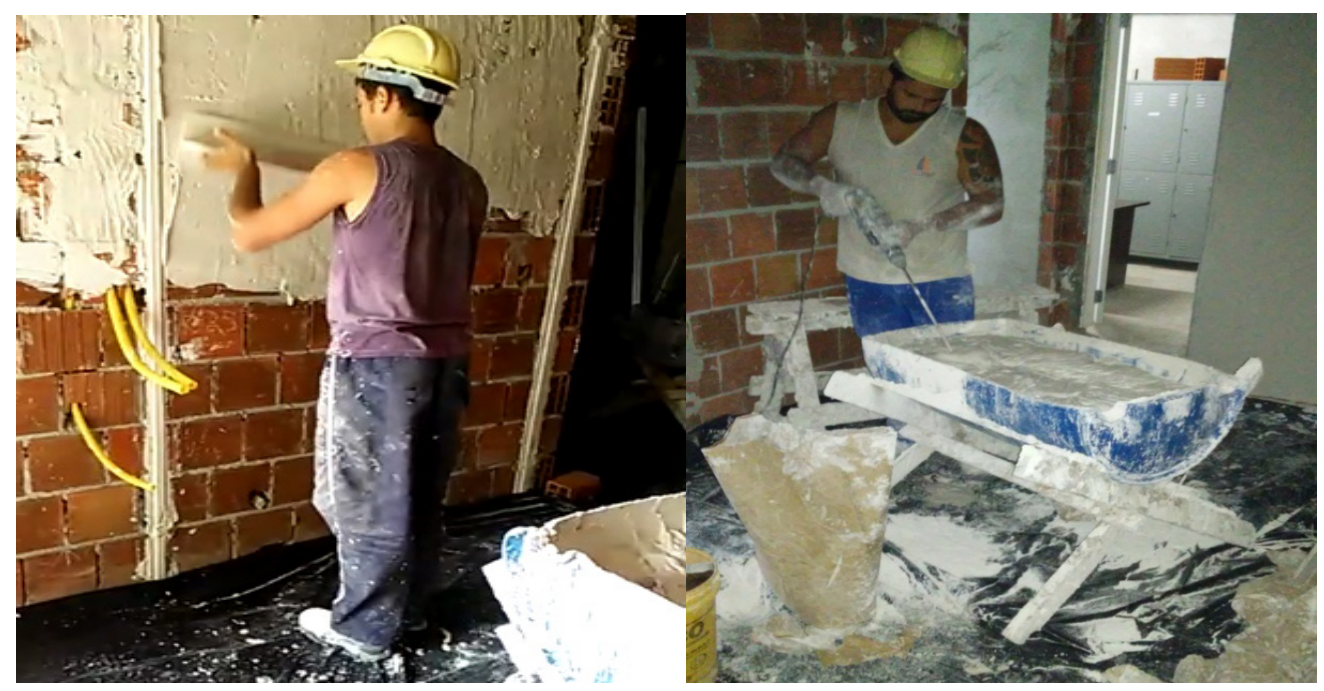

Fonte: Autores

\section{REVESTIMENTO EM GESSO, COM MISTURA E PROJEÇÃO MECANIZADA}

O preparo da pasta em gesso para revestimento foi executado através de um misturador acoplado à própria mangueira de projeção. Foram projetadas, por uma equipe de 3 gesseiros, camadas de gesso parede com o posterior sarrafeamento com réguas e desempenadeiras apropriadas, perfazendo uma área total de $125,39 \mathrm{~m}^{2}$

Para esse processo de revestimento foi subcontratada uma empresa com mão de obra especializada, uma vez que se faz necessário treinamento para operar a máquina de projeção e para aplicação da argamassa por ela pressurizada. 
Figura 4: Misturador e projetor mecanizado do gesso na parede

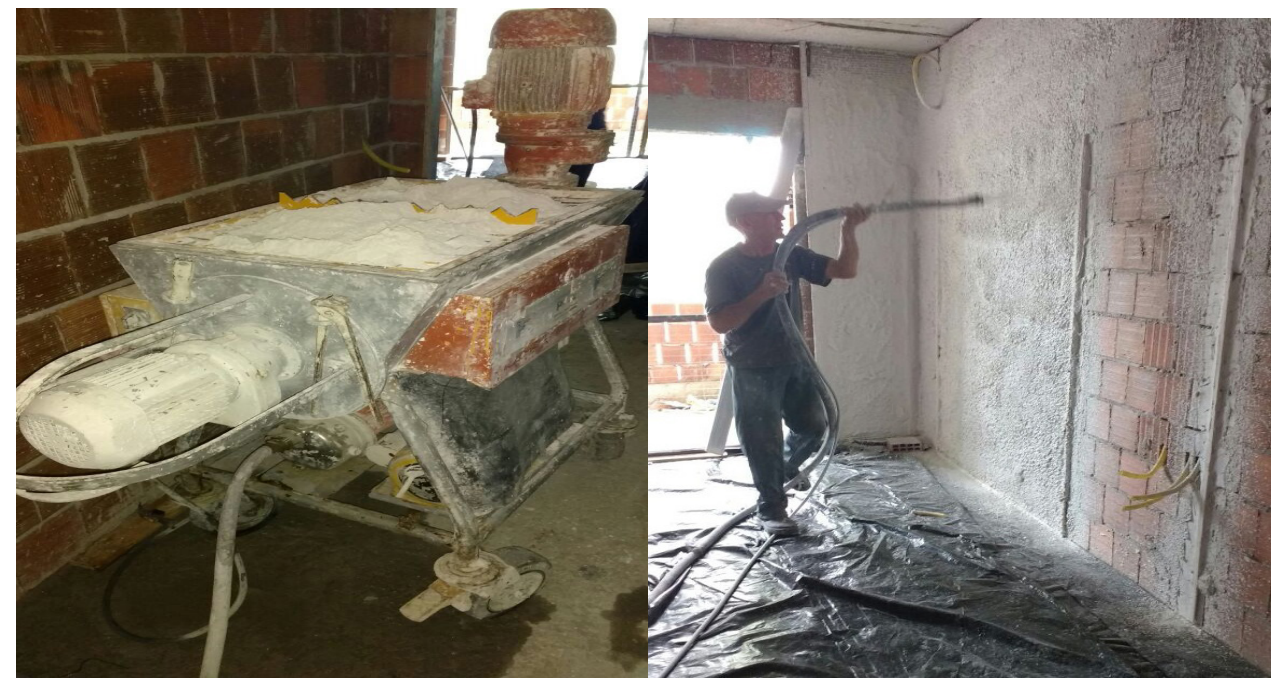

Fonte: Autores

REVESTIMENTO EM ARGAMASSA MISTA DE CIMENTO, CAL E AREIA, INDUSTRIALIZADA COM MISTURA E APLICAÇÃO MANUAL

O preparo da argamassa foi realizado com misturador mecânico de 120 litros instalado no pavimento da execução do serviço. A aplicação é feita com o lançamento da argamassa utilizando colher de pedreiro. O acabamento se dá por sarrafeamento com régua de alumínio. Todos esses serviços foram executados por uma equipe formada por um pedreiro e um servente, os quais revestiram $236,63 \mathrm{~m}^{2}$ de parede (Figura 5)

Figura 5: Misturador de argamassa e aplicação manual nas paredes

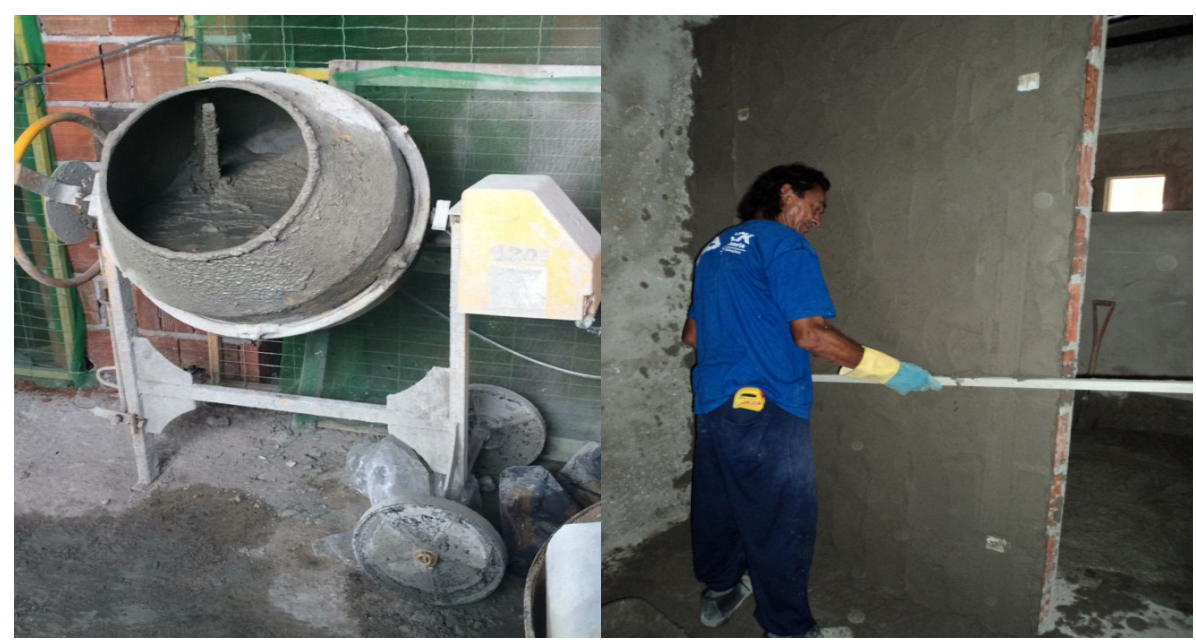

Fonte: Autores 


\section{REVESTIMENTO EM ARGAMASSA MISTA DE CIMENTO, CAL E AREIA, INDUSTRIALIZADA COM MISTURA E PROJEÇÃO MECANIZADA}

Assim como na argamassa de gesso projetado, o preparo e a aplicação da argamassa foram executados por uma equipe de 2 pedreiros, perfazendo $469,89 \mathrm{~m}^{2}$ de parede revestida.

O serviço com o projetor, assim como no caso do gesso projetado, foi executado por uma empresa terceirizada, por requer mão de obra especializada para operar a máquina de projeção e para aplicação da argamassa por ela pressurizada.

Figura 6: Misturador e projetor de argamassa mista

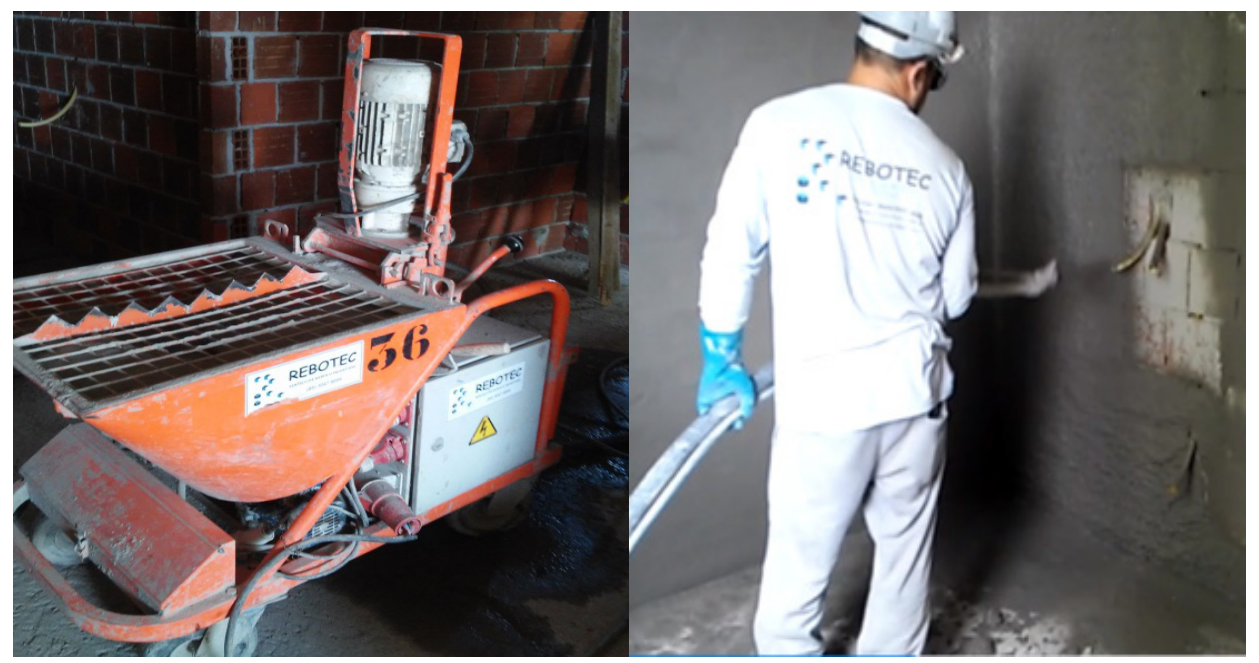

Fonte: Autores

\section{RESULTADOS E DISCUSSÃO}

\section{APROPRIAÇÕES DE PRODUTIVIDADE E CUSTOS UNITÁRIOS DOS SISTEMAS}

Os dados de insumos e produtividade foram coletados durante a execução dos revestimentos manualmente, conforme descrição na metodologia. O Quadro 1 apresenta os dados resultantes da produtividade por sistema.

Quadro 1: Dados de produtividade referente às áreas revestidas por tipo de revestimento

\begin{tabular}{|l|c|c|c|c|}
\hline \multicolumn{1}{|c|}{ Tipo de revestimento } & $\begin{array}{c}\text { Área executada } \\
\mathbf{m}^{\mathbf{2}}\end{array}$ & $\begin{array}{c}\text { Horas trabalhadas } \\
\mathbf{( e q u i p e )}\end{array}$ & $\begin{array}{c}\text { Produção } \\
\mathbf{m}^{2} / \mathbf{h}\end{array}$ & $\begin{array}{c}\text { Produção } \\
\mathbf{h} / \mathbf{m}^{2}\end{array}$ \\
\hline Gesso aplicação manual & 125,39 & 31 & 1,69 & 0,59 \\
\hline Gesso aplicação projetada & 52,43 & 54 & 2,32 & 0,43 \\
\hline Argamassa mista aplicação manual & 236,63 & 162 & 1,46 & 0,68 \\
\hline Argamassa mista aplicação projetada & 469,89 & 136 & 3,46 & 0,29 \\
\hline
\end{tabular}


Nota-se a maior produtividade do sistema de argamassa mista projetada.

Com os coeficientes de insumos calculados no quadro anterior e utilizandose como fonte de preços os valores repassados pelo departamento de compras da empresa construtora (data base 2017), apresenta-se os custos unitários para $1 \mathrm{~m}^{2}$ de revestimento de cada sistema, conforme os quadros 2, 3, 4 e 5:

Quadro 2: Composição de custos unitários da argamassa em gesso com mistura e aplicação mecanizada

\begin{tabular}{|c|c|c|c|c|}
\hline Insumo & Unidade & Quantidade & Valor Unitário & Valor Total por $\mathbf{~ m}^{\mathbf{2}}$ \\
\hline Super Revestimento & $\mathrm{Kg}$ & 22,33 & 0,416 & 9,29 \\
\hline Super Massa & $\mathrm{Kg}$ & 0,72 & 1,022 & 0,73 \\
\hline Cantoneiras & $\mathrm{Vb}$ & 1,00 & 0,199 & 0,20 \\
\hline Máquina + Gesseiro & $\mathrm{M}^{2}$ & 1,00 & 13,000 & 13,00 \\
\hline Frete & $\mathrm{Kg}$ & 23,05 & 0,132 & 3,04 \\
\hline Limpeza & $\mathrm{Vb}$ & 1,00 & 0,000 & 0,00 \\
\hline Encargos (horista) & $87,85 \%$ & 0,00 & 0,000 & 0,00 \\
\hline \multicolumn{7}{|l}{} & Total & $\mathbf{R} \mathbf{2 6 , 2 7}$ \\
\hline
\end{tabular}

Quadro 3: Composição de custos unitários da argamassa em gesso com aplicação manual

\begin{tabular}{|c|c|c|c|c|}
\hline Insumo & Unidade & Quantidade & Valor Unitário & Valor Total por $\mathbf{~}^{\mathbf{2}}$ \\
\hline Super Revestimento & $\mathrm{Kg}$ & 17,55 & 0,302 & 5,30 \\
\hline Super Massa & $\mathrm{Kg}$ & 0,00 & 1,022 & 0,00 \\
\hline Gesseiro & $\mathrm{m}^{2}$ & 1,00 & 5,682 & 5,68 \\
\hline Frete & $\mathrm{Kg}$ & 17,55 & 0,132 & 2,32 \\
\hline Limpeza & $\mathrm{Vb}$ & 1,00 & 0,000 & 0,00 \\
\hline Encargos & $87,85 \%$ & 1,00 & 5,259 & 5,26 \\
\hline \multicolumn{2}{|l}{} & Total & $\mathbf{R} \mathbf{1 8 , 5 6}$ \\
\hline
\end{tabular}

Quadro 4: Composição de custos unitários da argamassa mista com aplicação manual

\begin{tabular}{|c|c|c|c|c|}
\hline Insumo & Unidade & Quantidade & Valor Unitário & Valor Total por $\mathrm{m}^{2}$ \\
\hline Massa Pronta & $\mathrm{Kg}$ & 36,72 & 0,233 & 8,57 \\
\hline Pedreiro & $m^{2}$ & 1,00 & 4,306 & 4,31 \\
\hline Servente & $\mathrm{h}$ & 0,35 & 4,400 & 1,53 \\
\hline Encargos & $87,85 \%$ & 1,00 & 7,336 & 7,34 \\
\hline & & & Total & R\$ 21,74 \\
\hline
\end{tabular}

Quadro 5: Composição de custos unitários da argamassa mista com aplicação mecanizada

\begin{tabular}{|c|c|c|c|c|}
\hline Insumo & Unidade & Quantidade & Valor Unitário & Valor Total por $\mathrm{m}^{2}$ \\
\hline Reboco Jet & $\mathrm{Kg}$ & 31,28 & 0,283 & 8,86 \\
\hline Máquina+ Pedreiro & $\mathrm{m}^{2}$ & 1,00 & 14,000 & 14,00 \\
\hline Limpeza & $\mathrm{Vb}$ & 1,00 & 0,000 & 0,00 \\
\hline Encargos & $87,85 \%$ & 0,00 & 0,000 & 0,00 \\
\hline & & & Total & RS 22,86 \\
\hline
\end{tabular}


As composições mostram um menor preço do sistema manual de aplicação de gesso.

\section{DESEMPENHO DOS SISTEMAS}

Para o cálculo do desempenho referente à aderência dos sistemas, foi contratada um laboratório para a realização do respectivo ensaio. Apresenta-se a seguir, as imagens dos corpos de prova extraídos (figura 7):

Figura 7: Corpos de prova extraídos

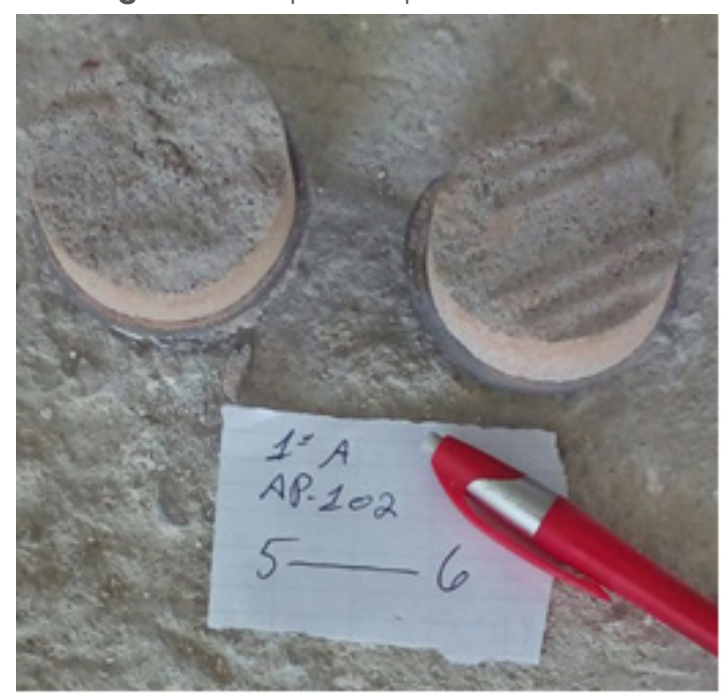

Fonte: Autores

Apresenta-se no quadro 6, um dos boletins com os resultados fornecidos pelo laboratório contratado:

Quadro 6: Boletim do ensaio à resistência

RESISTÊNCIA DE ADERÊNCIA À TRAÇÃO DE REVESTIMENTO DE PAREDES DE ARGAMASSAS INORGÂNICAS

NBR 13528/2010 - Revestimento de paredes de argamassa inorgânicas - Determinação da resistência de aderência à tração

\begin{tabular}{|l|l|}
\hline \multicolumn{2}{|c|}{ INDENTIFICAÇÕES GERAIS } \\
\hline Temperatura no dia do ensaio: $29 \pm 1{ }^{\circ} \mathrm{C}$ & Unidade relativa no dia do ensaio: $68 \pm 2 \%$ \\
\hline Data do ensaio: $18 / 05 / 2017$ & Diâmetro das pastilhas: $50 \mathrm{~mm}$ \\
\hline Tipo de cola utilizada: Epoxi & Equipamento de corte: Serra copo diamantada \\
\hline Equipamento de tração: Alfa $3105 \mathrm{CS}$ & \\
\hline
\end{tabular}

\begin{tabular}{|c|l|}
\hline \multicolumn{2}{|c|}{ INFORMAÇÕES DO SISTEMA DE REVESTIMENTO } \\
\hline Substrato & Bloco Cerâmico \\
\hline Chapisco & $(\mathrm{x})$ Não $(\mathrm{x})$ Sim \\
\hline Argamassa & (ver observação) \\
\hline Tipo de Aplicação & $(\mathrm{x})$ Manual $(\mathrm{x})$ Mecânica \\
\hline Idade do revestimento & 28 dias \\
\hline
\end{tabular}

\section{INTER/SCIENTIA}

REVISTA INTERSCIENTIA | V. 7 | N. 1 | P. 242-256 | JAN-JUN/2019 


\begin{tabular}{|c|c|c|c|c|c|c|}
\hline \multicolumn{7}{|c|}{ RESULTADOS } \\
\hline CP & $\begin{array}{c}\text { M } \\
\text { Médio } \\
(\mathbf{m m})\end{array}$ & $\begin{array}{c}\text { Carga de } \\
\text { Ruptura } \\
(\mathbf{k g f})\end{array}$ & $\begin{array}{c}\text { Resistência de } \\
\text { aderência à } \\
\text { tração }(\mathbf{M P a})\end{array}$ & $\begin{array}{c}\text { Formas de } \\
\text { ruptura \% }\end{array}$ & $\begin{array}{c}\text { Espessura } \\
(\mathbf{m m})\end{array}$ & OBSERVAÇĀO \\
\hline 1 & 49 & 60,4 & 0,31 & Arg/Sub & 10 & Gesso Manual \\
\hline 2 & 49 & 55,4 & 0,29 & Arg/Sub & 10 & Gesso Manual \\
\hline 3 & 49 & 55,4 & 0,29 & Arg/Sub & 25 & Argamassa Projetada \\
\hline 4 & 49 & 76,6 & 0,40 & Arg/Sub & 25 & Argamassa Projetada \\
\hline 5 & 49 & 78,6 & 0,41 & Arg. & 15 & Gesso Projetado \\
\hline 6 & 49 & 5 & 0,35 & Arg/Sub & 15 & Gesso Projetado \\
\hline 7 & 49 & 117,6 & 0,61 & Subs/Chap & 10 & Argamassa Industrializada \\
\hline 8 & 49 & 56,4 & 0,29 & Subs/Chap & 10 & Argamassa Industrializada \\
\hline
\end{tabular}

\begin{tabular}{|c|}
\hline NOTA NORMATIVA \\
\hline $\begin{array}{c}\text { A NBR 13749/2013, coloca que o revestimento será aceito se pelo menos } 8 \text { (oito) corpos de prova } \\
\text { apresentarem valores iguais ou maiores que 0,20 MPa para revestimentos de argamassa internos }\end{array}$ \\
\hline
\end{tabular}

Nota-se que todos os corpos de prova atingiram o desempenho esperado quanto à resistência ao arrancamento mínima de extraído do sistema de execução com gesso projetado, não atingiu o limite normativo de 0,20 MPa, para paredes internas que receberão pinturas.

\section{O REVESTIMENTO COMO SUBSTRATO PARA A CAMADA DE PINTURA}

Usualmente em edificações, para a obtenção de um acabamento mais liso nas paredes internas sujeitas à pintura, aplicam-se demãos de massa corrida em PVA. As demãos se sucedem de acordo com a aspereza do revestimento de argamassa, o qual serve de substrato para receber a massa e, posteriormente, pintura.

Ressalte-se que o número de demãos influi na produtividade, como observado no local, pois a cada demão existe um tempo de espera para a secagem da massa, bem como o posterior lixamento da camada.

Na última coluna do quadro 7, apresenta-se a classificação do acabamento dos revestimentos, conforme parâmetros descritos na metodologia.

\section{ANÁLISE DOS RESULTADOS E ESCOLHA DO SISTEMA}

De posse dos vários elementos estudados nesse trabalho, junto com o departamento técnico da empresa foi feita a escolha do revestimento conforme análise dos dados apresentados no quadro 7 e os critérios adiante apresentados. 
Quadro 7: Análise dos resultados

\begin{tabular}{|l|c|c|c|c|}
\hline \multicolumn{1}{|c|}{ Tipo de revestimento } & $\begin{array}{c}\text { Produtividade } \\
\left(\mathbf{m}^{2} / \mathbf{h}\right)\end{array}$ & $\begin{array}{c}\text { Custo } \\
\left(\mathbf{R} \mathbf{S} / \mathbf{m}^{2}\right)\end{array}$ & $\begin{array}{c}\text { Resistêncía à tração } \\
\text { média }(\mathbf{M P a})\end{array}$ & Acabamento \\
\hline Gesso projetado & 2,32 & 26,27 & 0,34 & Ruim \\
\hline Gesso manual & 1,69 & 18,56 & 0,30 & Ótimo \\
\hline Argamassa mista manual & 1,46 & 21,74 & 0,45 & Ruim \\
\hline Argamassa mista projetada & 3,46 & 22,86 & 0,41 & Bom \\
\hline
\end{tabular}

O quadro trouxe a visão abrangente para que a empresa decidisse pelo sistema de gesso manual, que além do menor custo, apresentou ótimo acabamento, o qual certamente trará economia no consumo de massa corrida durante a pintura das paredes.

\section{CONSIDERAÇÕES FINAIS}

O estudo apresentado teve como objetivo comparar tecnologias de revestimentos internos em argamassa, comparando-se a aplicação tradicional do revestimento com a aplicação de forma projetada.

Apresentou-se um estudo de caso onde foram executados os tipos de revestimento em análise mostrando o processo de execução de cada sistema.

De posse desses dados a empresa, agregando análise dos custos indiretos da obra, escolheu a opção do revestimento em argamassa mista com mistura e aplicação mecanizada, considerando a análise dos parâmetros diversos citados nessa pesquisa, mesmo apresentando custos diretos $23 \%$ maiores em relação ao sistema mais barato. O grande ganho de produtividade da mecanização otimizou o cronograma da obra em questão, possibilitando a antecipação em quatro meses no prazo de conclusão do serviço. Como consequência, os custos indiretos diminuíram consideravelmente, equilibrando a aparente diferença monetária favorável à contratação de outros sistemas.

Diante do exposto, conclui-se que os objetivos foram atingidos, obtendo-se os parâmetros técnicos e de custos diretos da obra, para que a empresa pudesse decidir qual dos sistemas utilizaria como camada de revestimento interno.

Observa-se que os custos indiretos e financeiros, cruciais para a escolha do tipo de revestimento, não foram estudados nem divulgados pela empresa. Assim, como esses custos foram o elemento chave para escolha do sistema na edificação deste modelo ilustrativo, surge um bom tema para futuros trabalhos no âmbito da engenharia civil. 


\section{REFERÊNCIAS}

ASSOCIAÇÃO BRASILEIRA DE CIMENTO PORTLAND (ABCP). Manual de Revestimentos de Argamassa. São Paulo, 2002.

ASSOCIAÇÃO BRASILEIRA DE NORMAS TÉCNICAS - ABNT. NBR 7200: ExeCUÇão de revestimento de paredes e tetos de argamassas inorgânicas - Procedimento. Rio de Janeiro, 1998.

. NBR 13207: Gesso para construção civil. Rio de Janeiro, 1994.

. NBR 13281: Argmassa para assentamento e revestimento de paredes e tetos - requisitos. Rio de Janeiro, 2005.

.NBR 13528: Revestimento de paredes e tetos de argamassas inorgânicas

- Determinação da resistência de aderência à tração. Rio de Janeiro, 2010.

- NBR 13529: Revestimento de paredes e tetos de argamassas inorgânicas. Rio de Janeiro, 2013.

. NBR 13749: Revestimento de paredes e tetos de argamassas inorgânicas

- Especificação. Rio de Janeiro, 2013.

BAÍA, Luciana Leone Maciel; SABBATINI, Fernando Henrique. Projeto e Execução de Revestimento de Argamassa. São Paulo: O Nome da Rosa, 2000.

BERTOLINI, Luca. Materiais de Construção: patologia, reabilitação, prevenção. São Paulo: Oficinas de Textos, 2006.

GUIMARÃES, José Epitácio Passos. A Cal Fundamentos e Aplicações na Engenharia Civil. São Paulo: Pini, 1998.

YAZIGI, Walid. A Técnica de Edificar. 14. ed. São Paulo: Pini, 2014.

Recebido em: 17/12/2018.

Aceito em: 01/07/2019. 